\title{
Numerical Prediction of Feasibility to Lower Droplet Temperature in Duplex Current Feeding MIG Welding Process
}

\author{
by TASHIRO Shinichi**, AOKI Atsuhito***, KUROAWA Hideaki****, TANAKA Manabu**
}

\begin{abstract}
In the conventional MIG welding, it is difficult to control the droplet temperature because of the unique relationship between the welding current and the wire feed speed. This study aims to develop a novel MIG welding process with duplex current feeding (DCF-MIG), which enables to control the welding current and the wire feed speed independently by feeding the secondary current near the wire tip in addition to the conventional MIG current. In this paper, a feasibility to achieve lowering the droplet temperature using DCF-MIG welding was investigated through numerical analysis. Consequently, the decrease in the droplet temperature in the DCF-MIG welding was predicted to be feasible.
\end{abstract}

Key Words: MIG Welding, Pure Argon Shielding Gas, Metal transfer, Duplex Current Feeding, Droplet Temperature, Numerical Simulation

\section{Introduction}

Metal Inert Gas (MIG) welding is an arc welding process which uses a consumable wire electrode and widely used for manufacturing various industrial products, because it enables to weld materials with high efficiency.

However, a convex weld bead is known to be formed in MIG welding using pure inert shielding gas ${ }^{1}$, which leads to welding defects such as incomplete fusion between weld passes in multilayer welding. Therefore, mixture of argon with oxygen or carbon dioxide is generally used as the shielding gas, which contributes to decrease the surface tension of weld metal as well as to stabilize the arc ${ }^{2}$. In this case, the toughness of the base metal is largely decreased despite of the addition of only small amount of oxygen or carbon dioxide ${ }^{3}$. The convex welding bead produced in the conventional MIG welding using pure inert gas can be also prevented by increasing the weld metal temperature to reduce the surface tension. Hence, it is desirable to raise the droplet temperature for increasing the wettability.

On the other hand, in processes such as thin plate welding, overlaying, and dissimilar metal joining by brazing, a decrease in droplet temperature is required for preventing excessive heat input to the base metal. As described above, in MIG welding, there is a demand for controlling the droplet temperature over a wide range.

However, in the conventional MIG welding, it is difficult to control the droplet temperature because of the unique relationship between the welding current and the wire feed speed ${ }^{4,5}$.

This study aims to develop a novel MIG welding process with duplex current feeding (DCF-MIG), which enables to control the

\footnotetext{
${ }^{*}$ Received: 2019.11 .21

${ }^{* *}$ Member, Joining and Welding Research Institute Osaka University

****Member, Kawasaki Technology Co., Ltd.

${ }^{* * * *}$ Member, Kawasaki Heavy Industries, Ltd.
}

welding current and the wire feed speed independently by feeding the secondary current near the wire tip in addition to the conventional MIG current. In the previous study ${ }^{6-8}$, the equipment for the DCF-MIG welding was developed. Furthermore, basic characteristics in several welding conditions were experimentally clarified and those were compared with the conventional MIG welding. Figure 1 shows a schematic diagram of the DCF-MIG welding. As explained above, the additional feeding point (contact point) of the secondary current was established near the wire tip. The torch has the dual nozzle structure. The pure argon gas was introduced from both nozzles. The distance between the contact tip and the feeding point of the secondary current was $12 \mathrm{~mm}$. The DCF-MIG welding has two sets of welding power sources and current feeding points. The primary current with constant voltage characteristics and the secondary current with constant current characteristics were fed at the primary and secondary feeding points, respectively. Consequently, it was found that the droplet temperature in the DCF-MIG welding was higher than the conventional MIG welding. The convex welding bead was remarkably solved.

Then, mechanism and basic characteristics of DCF-MIG welding were also investigated by numerical simulation with a simplified DCF-MIG welding model ${ }^{9}$. . As a result, it was found that total welding current was largely increased by feeding the secondary current in addition to the primary MIG welding current under the same arc voltage and wire feed speed. Furthermore, the droplet temperature was also increased due to the increase in total welding current.

In the above studies, the increase in the droplet temperature was successfully achieved using DCF-MIG welding by independently controlling the wire feed speed and current. In this paper, a feasibility to achieve lowering the droplet temperature using DCF-MIG welding is also investigated through numerical analysis. 


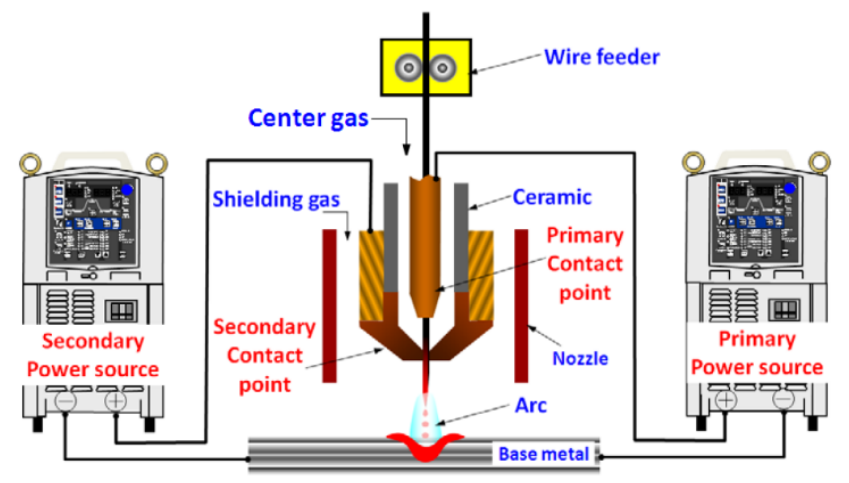

Fig. 1 Schematic diagram of duplex current feeding MIG welding.

\section{Simulation model}

In this study, mechanism and basic characteristics of duplex current feeding GMA welding are investigated by numerical simulation with a simplified duplex current feeding MIG welding model. Figure 2 shows an axisymmetric two-dimensional simulation domain $(\mathrm{r}, \mathrm{z})$ with a radius of $30 \mathrm{~mm}$ and a height of 30 $\mathrm{mm}$ consisting of an arc region and a wire region assuming stationary welding for simplicity. The height is the same as CTWD used in our previous experiments 6, 7). Sizes of meshes are approximately $0.1 \mathrm{~mm}$. Regions for a contact tip, a shielding gas inlet and a nozzle are defined on the top boundary. The outer diameter of the contact tip and the inner diameter of the shielding gas inlet are $2.4 \mathrm{~mm}$ and $14 \mathrm{~mm}$, respectively. On the axis, the wire region with the diameter of $1.2 \mathrm{~mm}$ and the extension of $25 \mathrm{~mm}$ corresponding to arc length of $5 \mathrm{~mm}$ is defined. In this model, the energy transport in the wire due to the wire feed and the energy loss due to the metal transfer are considered although the wire is assumed to be in solid phase and change in the wire extension and detachment of the droplet are ignored. The side boundary is pressure outlet. The bottom boundary corresponds to the surface of the base metal. The region inside the base metal are not calculated.

The primary current and the secondary current are in constant voltage characteristics and constant current characteristics, respectively. Although pulsed current was used for the primary current in the previous experiment, the direct current is used for the both current for simplicity. The primary current is fed from the wire region on the top boundary and changes by $0.01 \mathrm{~A}$ in each iteration to match the applied voltage to the setting voltage. In the previous study ${ }^{9)}$, the secondary current in positive polarity was fed at the point below $12 \mathrm{~mm}$ from the contact tip. On the other hand, the secondary current in negative polarity is given at this point in this study. The bottom boundary is set to be $0 \mathrm{~V}$. In this model, distributions of temperature, velocity and so on are obtained by solving the following equations assuming steady state.
Mass conservation:

$$
\nabla \cdot(\rho \vec{u})=0
$$

Momentum conservation:

$$
\begin{aligned}
& \nabla \cdot(\rho \vec{u} \vec{u})=-\nabla p+\nabla \cdot \overrightarrow{\vec{\tau}}+\rho \vec{g}+\vec{j} \times \vec{B} \\
& \overrightarrow{\vec{\tau}}=\mu\left(\nabla \vec{u}+\vec{u}^{T}\right)
\end{aligned}
$$

Energy conservation:

$$
\begin{aligned}
& \nabla \cdot(\rho h \vec{u})=\nabla \cdot(k \nabla T)+\vec{j} \cdot \vec{E}-R+Q_{s}-Q_{m t} \\
& Q_{s}=\left(j \phi-\varepsilon \alpha T^{4}\right) S_{s c} / V_{s c} \\
& Q_{m t}=\rho h_{d} u_{w} S_{w} / V_{d}
\end{aligned}
$$

Mass conservation of metal vapor:

$$
\begin{aligned}
& \nabla \cdot(\rho Y \vec{u})=\nabla \cdot(\rho D \nabla Y)+Q_{v} \\
& Q_{v}=\left(\sqrt{\frac{m}{2 \pi k_{B} T_{s}}} P_{v}\right) S_{c} / V_{c}
\end{aligned}
$$

Current conservation

$$
\nabla \cdot \sigma \nabla \Phi=0
$$

Ohm's law:

$$
\vec{j}=-\sigma \nabla \Phi=\sigma \vec{E}
$$

Vector potential:

$$
\nabla^{2} \vec{A}=-\mu_{0} \vec{j}
$$

Magnetic field:

$$
\vec{B}=\nabla \times \vec{A}
$$

Where $\rho$ : mass density, $\vec{u}$ : velocity, p: pressure, $\overrightarrow{\vec{\tau}}$ : viscus stress tensor, $\mu$ is viscosity, $\vec{g}_{\text {: gravity, }} \vec{j}_{\text {: current density, }} \vec{B}$ : magnetic field, $h$ : enthalpy, $k$ : thermal conductivity, $T$ : temperature, $\vec{E}$ : electric field, $R$ : arc radiation, $Q_{\text {s: }}$ electron condensation and surface radiation on the wire surface, $Q_{\mathrm{mt}}$ : energy loss in the wire due to metal transfer, $\phi$ : work function of the wire, $\varepsilon$ : surface emissivity, $\alpha$ : Stephan Boltzmann constant, $S_{\mathrm{sc}}$ : surface area of wire surface cell, $V_{\mathrm{sc}}$ : volume of wire surface cell, $h_{\mathrm{d}}$ : enthalpy of the droplet, $u_{\mathrm{w}}$ : wire feed speed, $S_{\mathrm{w}}$ : cross-sectional area of wire, $V_{\mathrm{d}}$ : volume of the droplet, $Y$ : mass fraction of metal vapor, $D$ : diffusion coefficient of metal vapor, $Q_{v}$ : evaporation rate of metal 
vapor, $m$ : atomic mass of metal vapor, $\mathrm{k}_{\mathrm{B}}$ : Boltzmann constant, $T_{\mathrm{s}}$ : surface temperature of the wire, $P_{\mathrm{v}}$ : saturation vapor pressure, $S_{\mathrm{c}}$ : surface area of cell, $V_{\mathrm{c}}$ : volume of cell, $\sigma$ : electrical conductivity, $\Phi$ : electric potential, $\vec{A}$ : vector potential.

The conservation equations of mass and momentum are solved only in the arc region. The source term $R$ is defined only in the arc region. The source terms $Q_{\mathrm{s}}$ and $Q_{\mathrm{mt}}$ are defined only in the wire region. The wire feed speed is given to the advection term in the energy conservation equation for considering the energy transport by the wire feed. It is assumed that the droplet is formed in the wire region above $1 \mathrm{~mm}$ from the wire tip. The temperature of each sell in the droplet is replaced to an averaged value in the entire droplet in each iteration assuming very large energy transport caused by convection. $Q_{\mathrm{mt}}$ is uniformly subtracted from the droplet.

The thermodynamic and transport properties of the arc under the LTE assumption are calculated as functions of temperature and metal vapor concentration ${ }^{10}$. The diffusion coefficient of metal vapor is taken from Ref. ${ }^{11)}$. Only iron is assumed for metal vapor composition. The thermodynamic and transport properties of mild steel are used for the wire ${ }^{12,13)}$.

Table 1 summarizes boundary conditions. Where $u_{\text {gas }}$ is the gas velocity corresponding to the shielding gas flow rate and $j_{1}$ is the current density of the primary current. In order to consider evaporation of metal vapor from the weld pool surface, temperature on the base metal is assumed to be $1800 \mathrm{~K}$ for $\mathrm{r}<=5$ $\mathrm{mm}$ and $300 \mathrm{~K}$ for $\mathrm{r}>5 \mathrm{~mm}^{14)}$. $\mathrm{P}_{\text {atm }}$ is an atmospheric pressure.

The wire feed speed is $8 \mathrm{~m} / \mathrm{min}$. The composition of the shielding gas is pure argon and the flow rate of that is $10 \mathrm{~L} / \mathrm{min}$. The setting voltage is $24 \mathrm{~V}$ used in the experiment. The secondary current is set to be five levels: $0,25,5075,100 \mathrm{~A}$ in negative polarity. The wire composition is assumed to be pure iron. The calculation is done with ANSYS Fluent 18.1

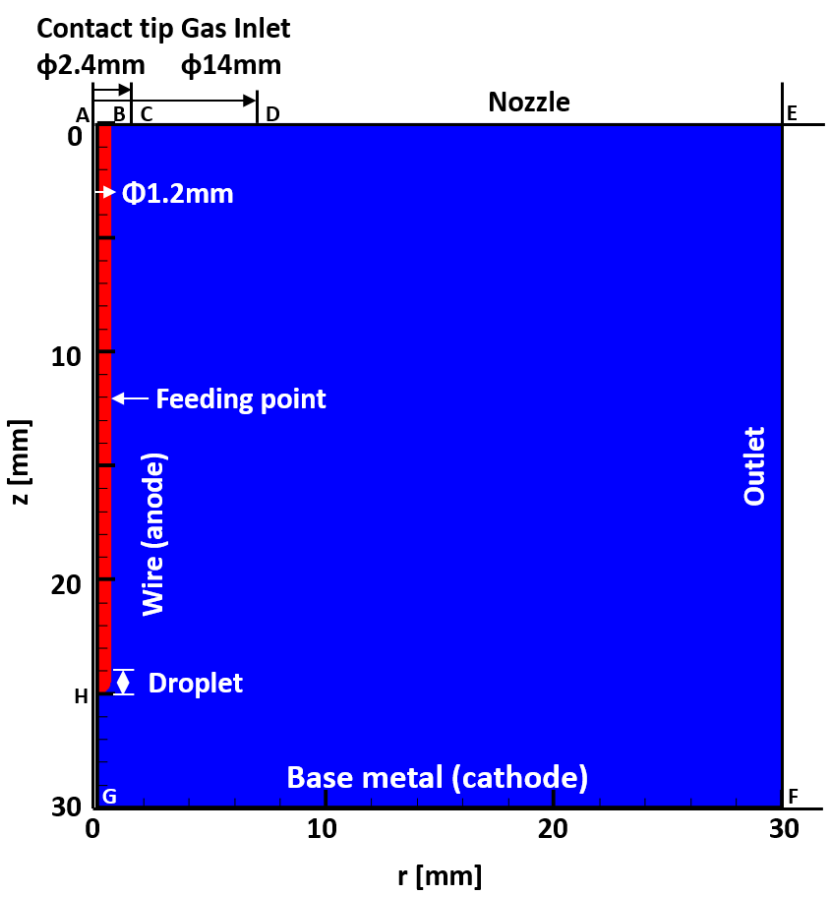

Fig. 2 Schematic diagram of simulation domain.

\section{Results and Discussion}

Figure 3 shows distributions of electric potential in the conventional MIG welding and DCF-MIF welding (the secondary current $\mathrm{I}_{2}$ of -100 A). It was seen that the electric potential was 24.0 $\mathrm{V}$ on the contact tip on the top boundary which was the same as the setting voltage. In the DCF-MIG welding, electric field in the wire increased above the feeding point of the secondary current comparing with that of the conventional MIG welding, but it conversely decreased below this point. Moreover, the electric field in the arc is seen to be higher in the DCF-MIG welding.

Figure 4 shows dependence of secondary current on primary current $I_{1}$ and total current $I_{\text {total }}$. The total current indicates the current below the feeding point of the secondary current corresponding to the value obtained by subtracting the secondary current from the primary current. The primary current was found to increase with the negative secondary current up to $75 \mathrm{~A}$.

Table 1 Boundary conditions

\begin{tabular}{|c|c|c|c|c|c|}
\hline Boundary & $\begin{array}{c}\text { Mass and } \\
\text { momentum }\end{array}$ & $\begin{array}{c}\text { Mass fraction of } \\
\text { metal vapor }\end{array}$ & Energy & Electric potential & $\begin{array}{c}\text { Magnetic } \\
\text { potential }\end{array}$ \\
\hline AB (Wire inlet) & - & - & $300 \mathrm{~K}$ & $-\sigma \partial \Phi / \partial \mathrm{n}=\mathrm{j}_{1}$ & $\partial \overrightarrow{\mathrm{A}} / \partial \mathrm{n}=0$ \\
\hline $\mathrm{BC}$ (Contact tip) & $\vec{u}=0$ & $\partial \mathrm{Y} / \partial \mathrm{n}=0$ & $300 \mathrm{~K}$ & $\partial \Phi / \partial \mathrm{n}=0$ & $\partial \overrightarrow{\mathrm{A}} / \partial \mathrm{n}=0$ \\
\hline $\mathrm{CD}$ (Gas inlet) & $\vec{u}=\vec{u}_{\text {gas }}$ & $\mathrm{Y}=0$ & $300 \mathrm{~K}$ & $\partial \Phi / \partial \mathrm{n}=0$ & $\partial \overrightarrow{\mathrm{A}} / \partial \mathrm{n}=0$ \\
\hline $\mathrm{DE}$ (Nozzle) & $\vec{u}=0$ & $\partial \mathrm{Y} / \partial \mathrm{n}=0$ & $300 \mathrm{~K}$ & $\partial \Phi / \partial \mathrm{n}=0$ & $\partial \overrightarrow{\mathrm{A}} / \partial \mathrm{n}=0$ \\
\hline $\mathrm{EF}$ (Gas outlet) & $\mathrm{P}=\mathrm{P}_{\text {atm }}$ & $\mathrm{Y}=0$ & $300 \mathrm{~K}$ & $\partial \Phi / \partial \mathrm{n}=0$ & $\overrightarrow{\mathrm{A}}=0$ \\
\hline FG (Base metal) & $\vec{u}=0$ & $\partial \mathrm{Y} / \partial \mathrm{n}=0$ & $\begin{array}{c}1800 \mathrm{~K}(\mathrm{r}<=5 \mathrm{~mm}) \\
300 \mathrm{~K}(\mathrm{r}>5 \mathrm{~mm})\end{array}$ & $\Phi=0$ & $\partial \overrightarrow{\mathrm{A}} / \partial \mathrm{n}=0$ \\
\hline GHA (Axis) & $\partial \vec{u} / \partial \mathrm{n}=0$ & $\partial \mathrm{Y} / \partial \mathrm{n}=0$ & $\partial \mathrm{T} / \partial \mathrm{n}=0$ & $\partial \Phi / \partial \mathrm{n}=0$ & $\partial \overrightarrow{\mathrm{A}} / \partial \mathrm{n}=0$ \\
\hline
\end{tabular}


However, it started to decrease above this current. Conversely, the total current monotonically decreased with the secondary current and especially steeply decreased above 75 A. Finally, it became $133 \mathrm{~A}$ at $100 \mathrm{~A}$. This is considered to be caused by lowering of the electrical conductivity of the arc due to the temperature decrease.

Figure 5 shows distributions of temperature in the conventional MIG welding and DCF-MIF welding (the secondary current $\mathrm{I}_{2}$ of $-100 \mathrm{~A}$ ). In case of conventional MIG welding, arc temperature reached around $14000 \mathrm{~K}$ at the maximum. The decrease in the temperature near the arc axis was caused by strong radiation loss due to dense metal vapour. On the other hand, the maximum temperature decreased below $10000 \mathrm{~K}$ in case of DCFMIG welding because of decrease in the total current.

Figure 6 shows dependence of secondary current on droplet temperature. The droplet temperature was found to be almost the constant value of $2250 \mathrm{~K}$ up to the negative secondary current of 50 A. The increase in the primary current raise the wire temperature above the feeding point of the secondary current due to Joule heating, but the decrease in the total current lower the heat input to the droplet due to electron condensation. Eventually, the droplet temperature hardly changed. Above $75 \mathrm{~A}$, both the primary current and total current decreased, leading to significant decrease in the droplet temperature to $1900 \mathrm{~K}$. In addition, the droplet temperature in case of $133 \mathrm{~A}$ of conventional MIG welding is also presented. The droplet temperature was found to decrease to approximately $1500 \mathrm{~K}$ which is lower than the melting point of the wire. This result means that the arc length can't be maintained due to insufficient melting rate of the wire in conventional MIG welding using the present wire feed speed, which proves one of the advantages to use DCF-MIG welding.

Consequently, it was predicted that the DCF-MIG welding enables to decrease the droplet temperature in a wide range. As a next step, we are also planning to confirm the result obtained in this study by experiments.

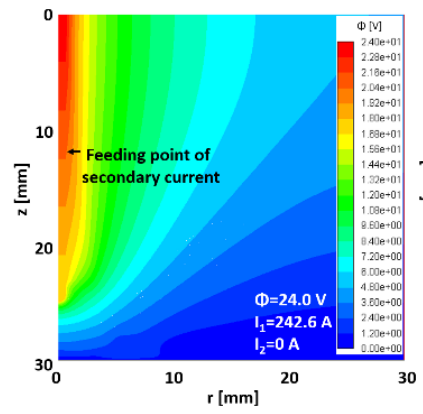

(a) Conventional

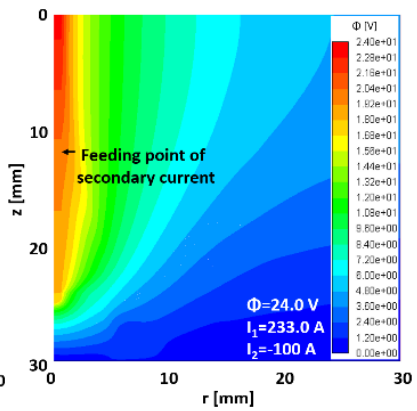

(b) Duplex current feeding

$$
\left(\mathrm{I}_{2}=-100 \mathrm{~A}\right)
$$

Fig. 3 Distributions of electric potential in conventional MIG welding and DCF-MIG welding $\left(\mathrm{I}_{2}=-100 \mathrm{~A}\right)$.

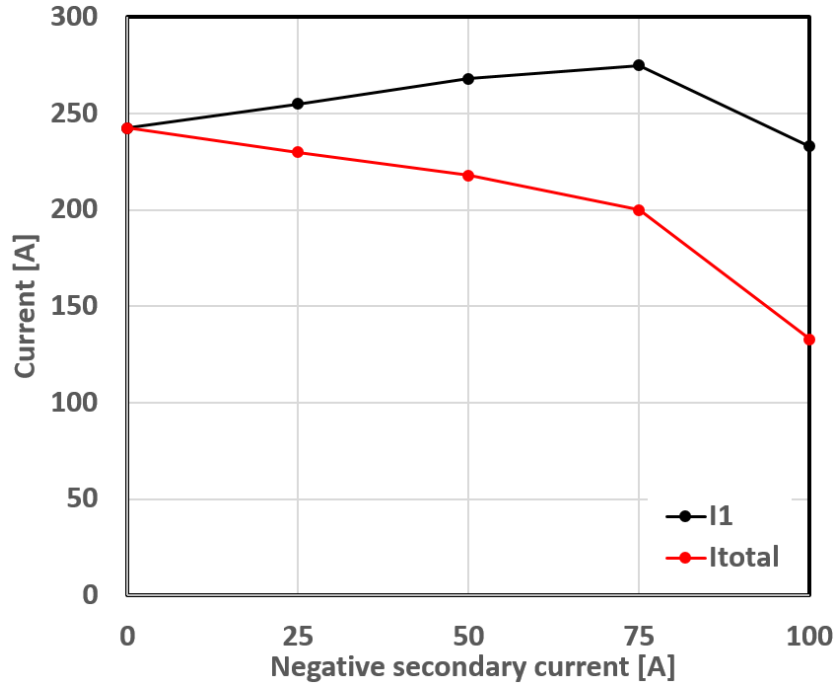

Fig. 4 Dependence of secondary current on primary current and total current.

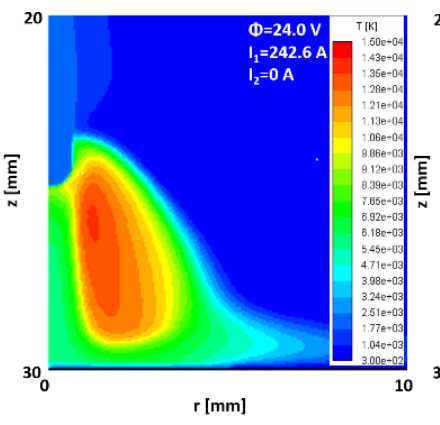

(a) Conventional

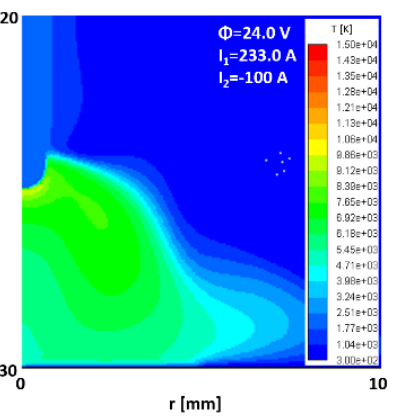

(b) Duplex current feeding $\left(\mathrm{I}_{2}=-100 \mathrm{~A}\right)$
Fig. 5 Distributions of temperature in conventional MIG welding and DCF-MIG welding $\left(\mathrm{I}_{2}=-100 \mathrm{~A}\right)$.

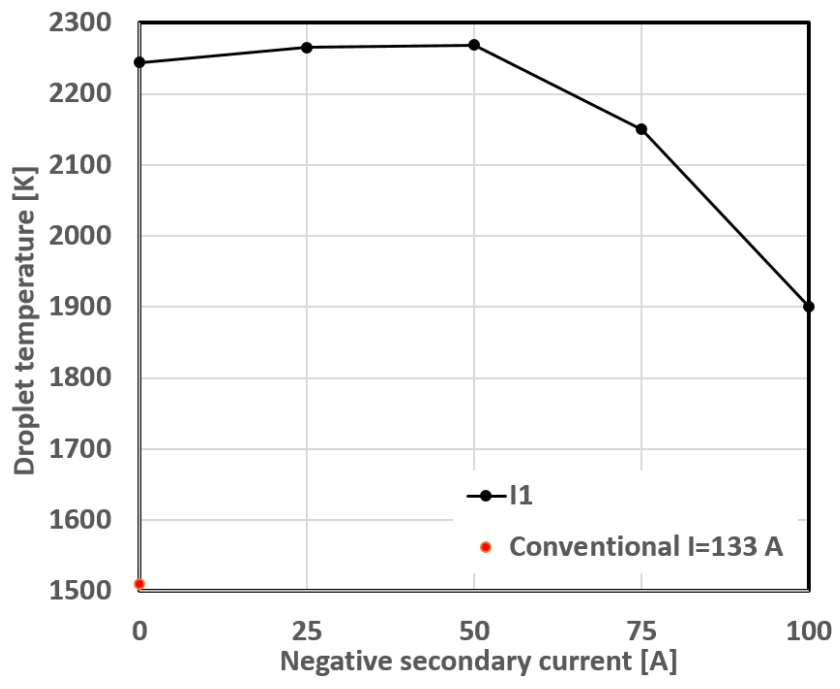

Fig. 6 Dependence of secondary current on droplet temperature.

\section{Conclusions}


In this paper, a feasibility to achieve lowering the droplet temperature using DCF-MIG welding was investigated through numerical analysis. Consequently, the decrease in the droplet temperature in the DCF-MIG welding was predicted to be feasible. As a next step, we are also planning to confirm the result obtained in this study by experiments.

\section{Reference}

1) S.A.David, T.Debroy, J.M.Vitek: "Phenomenological Modeling of Fusion Welding Process" MRS Bulletin, 10, 1 (1994), 29-35

2) T. Nakamura, K. Hiraoka: "GMA Welding of $9 \% \mathrm{Ni}$ steel in the pure Argon shielding gas using coaxial multi-layer solid wire", Quarterly J. Japan Welding Soc., 30, 3 (20012), 254-261

3) S. Terashima and K. K. D. H. Bhadeshia: "Change in toughness at low oxygen concentrations in steel weld metals", Science and Technology of Welding and Joining, 11, 5 (2006), 509-516

4) M. Tanaka, T. Tamaki, S. Tashiro, K. Nakata, T. Ohnawa, T. Ueyama : "Characteristic of ionized gas metal arc processing", Surface \& Coating Technology, 202 (2008), 5251-5254

5) K. Yamazaki, E. Yamamoto, K. Suzuki, F. Koshiishi, K. Waki, S. Tashiro, M.Tanaka, K. Nakata: "The Measurement of Metal Droplet Temperature in GMA Welding by Infrared Two-Color Pyrometry", Quarterly J. Japan Welding Soc., 26, 3 (2008), 214-219

6) M. Seto, A. Aoki, M. Tanaka, S. Tashiro, T. Era: "Study on new welding process with duplex current feeding” , Quarterly J. Japan Welding Soc., 34, 2 (2016), 150-157
6) M. Seto, A. Aoki, M. Tanaka, S. Tashiro, T. Era: "Study on new welding process with duplex current feeding” , Quarterly J. Japan Welding Soc., 34, 2 (2016), 150-157

7) A. Aoki, S. Tashiro, H. Kurokawa, and M. Tanaka: Development of novel MIG welding process with duplex current feeding, Journal of Manufacturing Processes, 47 (2019), 74-82

8) A. Aoki, S. Tashiro, H. Kurokawa, and M. Tanaka, "Influence of Current Feeding Position of Duplex Current Feeding MIG Welding on Droplet Heat Quantity, Materials, 12-21 (2019), 3590

9) S. Tashiro, M. Seto, A. Aoki, M. Tanaka: "Numerical simulation of new GMA welding process with duplex current feeding" , IIW Doc. 212-1434-16 (2016)

10) M Tanaka, $K$ Yamamoto, $S$ Tashiro, $K$ Nakata, $E$ Yamamoto, $K$ Yamazaki, K Suzuki, A B Murphy and J J Lowke: “Time-dependent calculations of molten pool formation and thermal plasma with metal vapour in gas tungsten arc welding", J. Phys. D: Appl. Phys., 43 (2010), 434009 (11pp)

11) M. Schnick, U. Fuessel, M. Hertel, A. Spille-Kohoff, and A. B. Murphy: "Numerical investigations of arc behaviour in gas metal arc welding using ANSYS CFX", Front. Mater. Sci., 5, 2 (2011), 98-108

12) M Hertel, A Spille-Kohoff, U F" ussel and M Schnick: "Numerical simulation of droplet detachment in pulsed gas-metal arc welding including the influence of metal vapour", J. Phys. D: Appl. Phys., 46 (2013), 224003 (11pp)

13) Y. Ogino, Y. Hirata, A. B. Murphy: "Numerical simulation of GMAWprocess using Ar and an Ar-CO2 gas mixture", Weld World, (2016), DOI 10.1007/s40194-015-0287-3

14) K. Yamazaki, E. Yamamoto, K. Suzuki, F. Koshiishi, S.Miyazako, S. Tashiro, M. Tanaka, K. Nakata: "The Surface Temperature Measurement of Weld Pool by Infrared Two-Color Pyrometry", Quarterly J. Japan Welding Soc., 27, 1 (2009), 34-40 